\title{
Machiavellians, Unethical Workmates And Intention To Stay: An Empirical Exploration
}

Pablo Ruiz Palomino, University of Castilla-La Mancha, Spain Ricardo Martínez Cañas, University of Castilla-La Mancha, Spain

\begin{abstract}
Machiavellianism is usually studied as an individual characteristic affecting an individual's ethical/unethical behavior in organizations, turning into an important influential factor in that matter. However, no studies have been conducted to date testing the influence of this personal trait on the individual's intention to stay, which on the basis of the theoretical perspective of the Resource-Based View of the Firm, have important valuable implications for the organization. Furthermore, no empirical research has been conducted in relation to test the comfort that Machiavellians experiment when an unethical climate is perceived in the organization. This paper will study the effect that a Machiavellian personality has on the individual's intention to stay and what happens if Machiavellians are within the organization in company of workmates who behave unethically in human interaction. Results obtained through the empirical analysis in a sample of Spanish banking employees are discussed and conclusions and implications both for academics and business professionals are presented.
\end{abstract}

Keywords: ethical/unethical workmates, value adjustment, intention to stay, Machiavellianism.

\section{INTRODUCTION}



he study of an employee's intention to stay is an area of both practical and theoretical importance in many academic disciplines (Psychology, Organizational Behavior, Human Resource Management and Economy, among others) (Cotton \& Tuttle, 1986; Griffeth, Hom \& Gaertner, 2000), surely due to the association which is supposed to exist between this individual job attitude and the direct and indirect consequences for the organization's global performance. However, it is surprising to see how little systematic knowledge is available about its causes or antecedents. In fact, although antecedents and correlates of turnover and turnover intention has been explored (e.g. Cotton \& Tuttle, 1986; Griffeth et al., 2000), the important role played by moderators of antecedent-turnover relationships is still an underexplored topic (Griffeth et al., 2000). As optimal knowledge of these moderators may lead to an opportunity to better understand the mechanisms affecting the individual's intention to stay, this research attempts to study in depth such aspect in literature and for this purpose focuses the attention on two potential predictors of the individual's intention to stay at present. On the one hand, as previous research indicates that an ethical environment influences job attitudes of the employees (Valentine, Greller \& Richtermeyer, 2006), we try to analyze the relationship which is suggested to exist between unethical workmates and the individual's intention to stay. On the other hand, and drawing from the findings and suggestions of some previous research (Griffeth et al., 2000), we also focus the attention on the role that the individual's degree of machiavellian personality plays in explaining such job attitude, but not only regarding direct effects but also the interactive effects that may happen between this variable and the contextual aspect aforementioned. The consideration of both aspects in research may allow us to contrast if, as Machiavellians are considered to be prone to behave unethically (Collins, 2000) and even with respect to others (Christie \& Geis, 1970; Hunt et al., 1985), Machiavellians are or not in reality more comfortable when workmates are unethical. 
The paper proceeds as follows. We first explain the theoretical framework and the derived hypothesis. A description of the research method and main results found in this study is provided next. Finally, a summary is presented in which we outline possible limitations, contributions and implications for future research.

\section{THEORETICAL BACKGROUND AND HYPOTHESES}

\section{Workmates' immorality and intention to stay}

In general, people prefer an ethical working environment as this is the context in which they feel better when providing their job effort (Trevino \& Nelson, 2004). Accordingly, intention to stay is expected to be strongly influenced by the level of morality which is perceived in the organizational context. Some empirical research supports such suggestion, by finding that in those environments in which immorality is common or facilitated by Top Management, intention to stay is significantly diminished (Peterson, 2003). Drawing on these findings, the individual's stay in those organizations where workmates are unethical is suggested to be uncomfortable for individuals, especially when workmates have a tendency to develop immoral actions in the treatment with other people. Indeed, living and working in environments where other individual's actions are focused on denigrating other people, does not seem to be the optimal context that any individual needs in order to self-satisfy human needs, and what is more important, excel him/herself. As a consequence, inconformity with the organization in which individuals are working is expected if workmates' immorality is perceived, and therefore, the individual's intention to stay in the organization may be negatively affected. We can express this idea formally as follows:

$\mathbf{H}_{\mathbf{1}}$ : "Workmates' immorality will have a negative effect on the individual's intention to stay"

\section{Machiavellianism and intention to stay}

From the $16^{\text {th }}$ century writings of Florentine Niccolo Machiavelli, the notion of Machiavellianism (Mach from now on) has been traditionally linked to a negative personality trait leading the individual to immorality (Collins, 2000). Indeed, Mach personality is usually linked to the development of certain tactics and actions of a manipulative, persuasive and deceitful nature which are used in order to have influence and power on others (Hunt \& Chonko, 1984). As they are linked to strongly desire the power of others (Christie \& Geis, 1970), they perceive the rest of the individuals as mere objects to be manipulated (Christie \& Geis, 1970), and they may behave unethically in order to satisfy their self-interests. Therefore, since these personality traits are not thought to be welcomed by others, Machs usually engage in a variety of influence tactics (e.g. self-disclosure, ingratiation, intimidation) in order to hide their true personality (Wilson, Near \& Miller, 1996), and at the same time, to capitalize on their exploitative skills. However, as the knowledge of such personality may become widespread through the years, Machs have a higher intention of leaving their current organizations than others (Wilson et al., 1996). Some previous research suggests such statement as it has been found that in a trust game setting in which all participants could profit, Machs tend to decide to defect with maximal benefits for themselves rather than reciprocate the trust shown by the other participants (Gunnthorsdotir, McCabe \& Smith, 2002). In line with the above arguments we formulate the following hypothesis:

\section{$\mathbf{H}_{2}$ : "A Machiavellian personality will have a negative effect on the individual's intention to stay"}

\section{Interactive effects of variables: the role of "workmates-individual" values-fit}

Although both contextual factors and individual variables are stated to have, individually, an important influence on the individual's intention to stay, literature also posits that the "person-organization" (P-O, from now on) fit plays an important role in that matter. Indeed, interaction of both groups of variables is widely known to probably explain, a greater variance in job attitudes and behaviours (Hackman \& Oldham, 1980). Indeed, as the P-O fit is defined as the extant congruence between beliefs, standards and/or organizational/individual values (Chatman, 1989), necessities, wishes and individual preferences are said to be strongly influenced by such variable (Chatman, 1989) and also the employees' job response. Therefore, drawing on this fact, as the "workmates-individual" values rate is better fitted, the individual's intention to stay into the organization is also suggested to be promoted (KristoffBrown, Zimmerman \& Johnson, 2005), which means that Machiavellianism may interact with workmates' 
immorality in explaining the individual's intention to stay. As has been afore described, Machiavellian personality may be perfectly defined as a personality structure leading to immorality (Collins, 2000). Then, Machiavellians may find their working climates more comfortable when workmates are of a similar nature since they do not have the need to either hide their true personality or be worried about if their true nature is overcome by others in the organization. Therefore, Machiavellianism may interact with workmates' immorality in explaining the individual's intention to stay in such a way that the individual's intention to stay is strengthened. From these arguments, the following hypothesis can be posited:

$\mathbf{H}_{3}$ : 'Workmates' immorality will have a weaker negative effect on the individual's intention to stay among employees with a high Machiavellian personality than among employees with a low Machiavellian personality"

\section{METHODOLOGY}

\section{Sample and procedure}

A survey instrument was used to gather data to test the relationships shown in the research model. Surveys were handed to a sample of 4,164 Spanish banking employees and confidentiality was assured. Once the process of collection of information was finished, 436 usable surveys were received, which implies a response rate of $10.5 \%$, very reasonable in the research subject of organizational behavior (Valentine et al., 2006). Suggestions were considered in order to avoid the problem of common method variance (Podsakoff, MacKenzie, Lee \& Podsakoff, 2003) and results from the one-factor Harman test confirmed the absence of this problem.

\section{Measures}

When measures are used to examine a latent construct that is unobservable, a choice between reflective or formative indicators must be made (MacKenzie, Podsakoff \& Jarvis, 2005). Thus, indicators may be caused by the latent construct and all of them highly correlate between them (reflective measures) or may determine the construct and are not necessarily correlate between them (formative measures) (Hulland, 1999). Once Mackenzie et al's (2005) recommendations for distinguishing between reflective and formative constructs were considered, we finally decided that our survey had a combination of both type of measures, reflective approaches for "Machiavellianism" and "intention to stay" variables, and a formative approach for measuring the Workmates' level of immorality.

In order to measure workmates' immorality, a selection of three formative observable indicators adapted from another study (E.R.C., 2005) was considered. All of those items made reference to three distinct unethical aspects of human interaction with direct negative effects on focal others (bullying, discrimination and verbal abuse), and the level of frequency in which those actions were committed by workmates ( $1=$ never, $5=$ very often) was the issue asked to interviewees. With regard to the measure for Machiavellianism, we used a ten item scale designed by Allsopp, Eysenck and Eysenck (1991) which had been successfully used by McCutcheon (2003). This scale was rated with a five-point scale anchored by 1 (strongly disagree) and 5 (strongly agree) and responses were averaged for each individual in such a way that higher scores indicated a stronger Machiavellian personality in the individual (e.g. "I enjoy manipulating people"). Finally, the turnover intention three-item scale validated by Konovsky and Cropanzano (1991) was selected for this study. Responses to this measure were rated from 1 (strongly disagree) and 5 (strongly agree), and higher averaged values for this scale indicated increased intention to stay by the respondant (e.g. "I intend to remain with this organization indefinitely").

A section of demographic aspects (level of education and organizational tenure) was also included in the present study, as they are of interest to any study aimed at explaining attitude and behavioral aspects.

\section{Data Analysis}

The data was analyzed using Partial Least Squares (PLS) since it is adequate in developing and constructing theory (Wold, 1979) -as pursued in this research-, and is the only structural equation modeling technique which allows the inclusion of both reflective and formative measures in a single analysis (Chin, 1998). 
Accordingly, the PLS via PLS-Graph 3.00 (Chin, 2003) was used for hypothesis testing and the stability of the estimates was tested via a bootstrap re-sampling procedure (500 sub-samples) as recommended by Chin (1998).

\section{RESULTS}

With regard to the measurement model for all the reflective latent constructs, only some problems were found with the individual reliability of 2 items of the scale of Machiavellianism. As suggested by Barclay et al. (1995) and Chin (1998), a trimming process for these items took then place so no further problems in terms of individual reliability were found. Moreover, additional analyses did not find problems with construct reliability, convergent and discriminant validity so the measurement model for reflective constructs is satisfactory. Since a formative construct was designed for the study (Workmates' unethicality), an examination of the weights estimates for its corresponding indicators was conducted. As levels of collinearity among the formative indicators are far below the common cut-off threshold of 5 to 10 (Kleinbaum, Kupper \& Muller, 1988), multicollinearity does not seem to be a problem in the present study, leading to observe different contributions and relative importance for all the formative indicators in the making up of the construct.

Once the measurement model was satisfactorily assessed both for reflective and formative constructs, we began to focus the attention on the evaluation of the structural model. As can be seen in Figure 1, on the basis of this empirical data, the proposed model is completely supported. On the one hand, in relation to the influence of workmates' immorality on employee's intention to stay, we have found a negative and significant association in support of Hypothesis H1 $(\beta=-.249 ; \mathrm{p}<.001)$. On the other hand, hypothesis H2 was supported, and as a consequence, the negative relationship predicted between the possession of a Machiavellian personality and the individual's intention to stay was confirmed $(\beta=-.120 ; \mathrm{p}<.01)$. Finally, as predicted, the possession of Machiavellianism negatively moderates the relationship between workmates' immorality and the individual's intention to stay $(\beta=-.139 ; \mathrm{p}<.05)$ in such a way that the aforementioned relationship is somehow weakened.

Figure 1

Interacting effect: comparative analysis of models

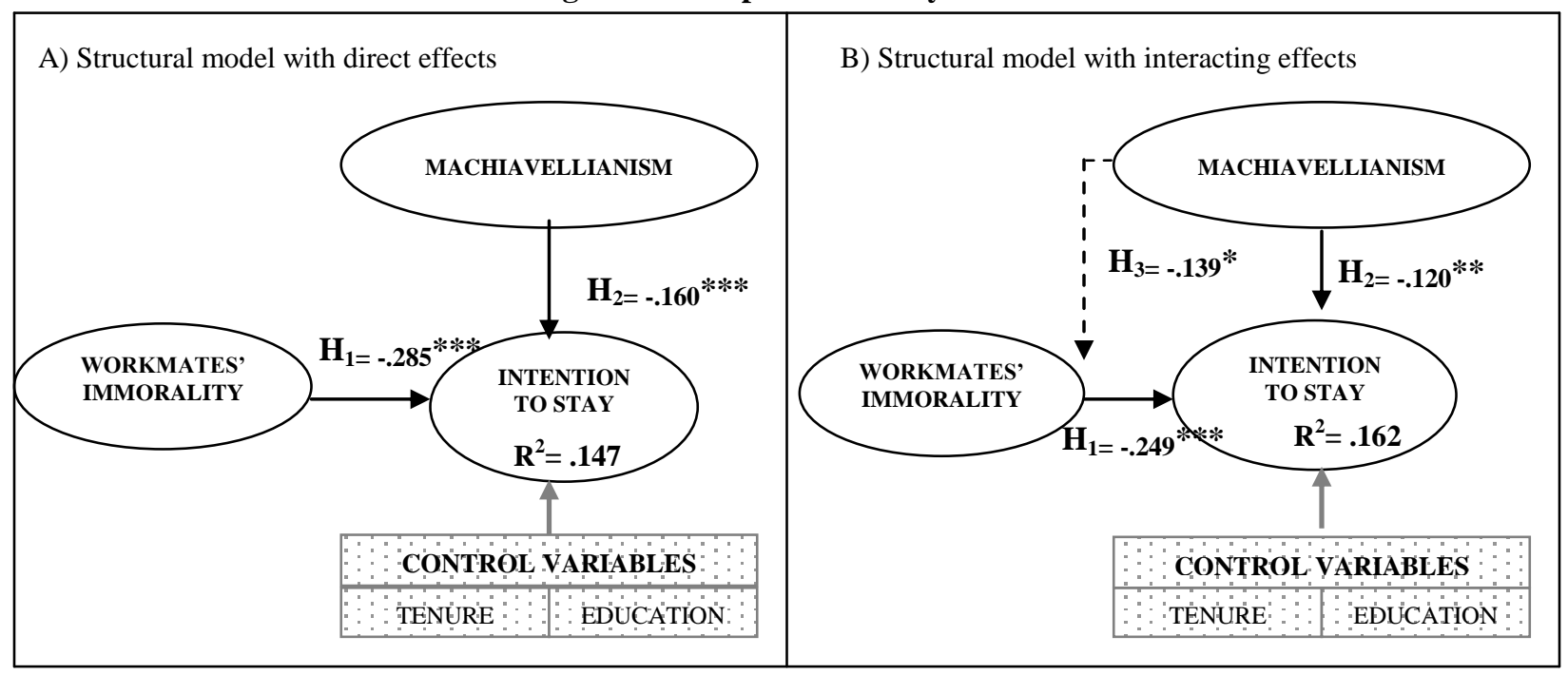

Notes: $* * * \mathrm{p}<.001, * * \mathrm{p}<.01, * \mathrm{p}<.05$ (based on a Student $\mathrm{t}{ }_{(499)}$ one-tailed test): $\mathrm{t}(0.001 ; 499)=3.106644601 ; \mathrm{t}(0.01 ; 499)$ $=2.333843952$ and $\mathrm{t}_{(0.05: 499)}=1.64791345$.

Regarding the demographical variables' effect on the dependent variable, the level of education had a significant role, specifically a negative effect on the employee's intention to stay $(\beta=-0.090 ; p<0.10)$. This result may be explained by the fact that as the individual possesses a higher level of education, he/she perceives him/herself with more capacity of reaching better jobs in better organizations. 
Table 1

Direct effects, explained variance and strength of interaction

\begin{tabular}{|c|c|c|c|}
\hline Effects on the dependent variable & $\begin{array}{l}\text { Direct effects } \\
\text { t-value }\end{array}$ & $\begin{array}{c}\Delta \text { Variance } \\
\text { due to interaction }\end{array}$ & $\begin{array}{l}\text { Strength of interaction } \\
\qquad\left(f^{2}\right)\end{array}$ \\
\hline Intention to stay $\left(\mathrm{R}^{2}=.162\right)$ & & .015 & .018 \\
\hline$H_{I}:$ Workmates' immorality & $-.249 * * *$ & & \\
\hline $\mathrm{H}_{2}:$ Machiavellianism & $-.120 * *$ & & \\
\hline
\end{tabular}

Notes: *** $\mathrm{p}<.001, * * \mathrm{p}<.01, * \mathrm{p}<.05$ (based on a Student $\mathrm{t}{ }_{(499)}$ one-tailed test) $f^{2}=\left(\mathrm{R}_{\text {included }}^{2}-\mathrm{R}_{\text {excluded }}^{2}\right) /\left(1-\mathrm{R}_{\text {included }}^{2}\right.$; Effect sizes of $f^{2} \leq .02, \leq .15$ and $\leq .35$ are regarded as weak, moderate and strong, respectively (Chin,1998).

All in all, through using the $R^{2}$ values of the endogenous construct to assess model fit, it can be stated that our research model has an appropriate predictive power. The endogenous variable is explained in a percentage higher than $10 \%$ which is the optimal minimum according to Falk and Miller (1992). Furthermore, the proposed interactive model can be stated to present a better explanation of the individual's intention to stay than the model with no interactive effects. Firstly, once calculated $f^{2}$ for mediating effects size in agreement with the Chin's (1998) criteria, Machiavellianism moderates, although weakly, the relationship between Workmates' immorality and the employee's intention to stay $\left(f^{2}=.018\right)$ (see Table 5). Secondly, the interactive model explains more variance of the endogenous variable of the model $\left(R^{2}=.162\right)$ than the direct model $\left(R^{2}=.147\right)$.

\section{DISCUSSION}

The results of this study revealed that workmates' immorality had a significant negative effect on the individual's intention to stay. In consistency with previous research (Peterson, 2003; Valentine et al., 2006), individuals may be drawn to leave the current organization when they perceive that their work environment is characterized by a high frequency of immorality. Similarly, results showed that Machiavellianism negatively influenced the individual intention to stay, which confirmed previous suggestions on the existence of such relationship (e.g. Wilson et al., 1996). As can be seen, since Machiavellians, in an attempt to accomplish personal objectives and interests, use any strategic tactic -no matter if moral or immoral-, they know that they can not be working with the same group of workmates for a long time. Their true manipulative and immoral nature will be finally overcome, and for this reason, they seem to have, in contrast with other people, a greater interest in leaving their current work environments. Finally, interactive effects were found between the organizational and the individual variables included in such a way that the degree of Machiavellianism that any individual possesses seems to moderate (weakening) the negative influence exerted by the workmates' immorality on the individual's intention to stay. Thus, the organization should match the individual's personality and values with the organization's values and culture, if a high rate of employee retention is desired. More specifically, as examined in this research, the organization should make sure that in the process of selecting future employees, the individuals who are going to work together share similar values and personality. Individuals are more likely to remain in organizations that provide a positive match in that matter so if advantages from efforts dedicated to recruiting, selecting and training individuals, and also the advantages of an experienced workforce, wish to be maintained, care should be taken in checking the personal traits of candidates.

As a concluding remark, our findings question the simplistic approach sometimes found in literature on the causes affecting the individual's intention to stay. In addition, results obtained in this study allow for advancement in knowledge of an individual's characteristics which is considered to have important implications for organizations (Dahling, Withaker \& Levy, 2008). Which is more important, through this study, we contribute to literature not only by confirming other individual characteristics as an important influential factor in explaining the individual's intention to stay. We also contribute by confirming that in understanding the causes leading an individual to stay in/leave an organization, the interactive effects between individual and contextual variables must be taken into consideration by managers.

Several limitations in this study should be considered. One of these limitations is that this research took place only within one industry -banking- and in a specific cultural context -Spain-, so although it is very probable 
that results may be repeated in other similar contexts, the external validity and spread of our results beyond the subjects of this study is limited. Another limitation is that the dependent variable of this study is of an intentional character, and although empirical and theoretical arguments exist on the suitability of using it as an immediate precursor of the individual's real action (Ajzen \& Fishbein, 1980), some other arguments support that the final individual's real response may vary due to several other constrictions (Hunt \& Vitell, 1993). Age may be one of these logical constrictions although a more interesting factor would be the level of virtuosity of the individual, because although the individual wants to exit the company, if he/she does not have the necessary courage to do it, he/she may finally decide to remain due to the probable fear of not being hired again.

In terms of additional lines of research, we see many interesting directions in order to provide further insights into the complex nature of the causes affecting the employee intention to stay. An obvious line of research is to analyze the influence of many other individual characteristics on such job attitude in such a way that the knowledge on the influential causes on the individual intention to stay can be improved. In addition, the interactive effects between other individual characteristics and organizational variables already found to individually affect this job attitude should be addressed in future studies. Further research should also utilize a variety of data collection methods in order to objectify results obtained in this research. Finally, future studies should test whether findings of this research apply to other industries and cultural regions, and also if Machiavellianism possesses other significant effects on other type of job attitudes and behavior.

\section{AUTHOR INFORMATION}

Pablo Ruiz-Palomino: PhD in Business Administration and Degree in Business Administration by University of Castilla-La Mancha. Assistant Professor at Business Management. Faculty of Social Sciences of Cuenca. University of Castilla-La Mancha (Spain). E-mail: Pablo.Ruiz@uclm.es.

Research Interest: business ethics and social capital.

Ricardo Martínez-Cañas: PhD in Business Management and Degree in Business Administration by University of Castilla-La Mancha. Assistant Professor at Business Management Department. Faculty of Social Sciences of Cuenca. University of Castilla-La Mancha (Spain). E-mail: Ricardo.Martinez@uclm.es.

Research Interest: organizational social capital, science parks, business ethics and leadership.

\section{REFERENCES}

1. Ajzen, I. \& Fishbein, M. (1980). Understanding Attitudes and Predicting Social Behaviour. Englewood Cliffs, NJ: Prentice Hall.

2. Allsopp, R.J., Eysenck, H.J. \& Eysenck, S.B.G. (1991). Machiavellianism as a Component in Psychoticism and Extraversion. Personality and Individual Differences, 12, 29-41

3. Barclay, D., Higgins, C. \& Thompson, R. (1995). The Partial Least Squares (PLS) approach to causal modelling: personal computer adoption and use as an illustration, Technology Studies, Special Issue on Research Methodology, 2 (2), 285-309.

4. Chatman, J. (1989). Improving interactional organizational research: A model of Person-Organization fit. Academy of Management Review, 14 (3), 333-349.

5. Chin, W. W. (1998). The Partial Least Squares Approach to Structural Equation Modelling. In G.A. Marcoulides (Ed.), Modern Methods for Business Research (pp. 295-336). New York: Lawrence Erlbaum Associates.

6. $\quad$ Chin, W.W. (2003). PLS-Graph, Version 3.00 (Build 1130), Texas: University of Houston.

7. Christie, R. \& Geis, F.L (1970). Studies in Machiavellianism. New York: Academic Press.

8. Collins, D. (2000). The quest to improve the human condition: The first 1500 articles published in Journal of Business Ethics. Journal of Business Ethics, 26, 1-73

9. Cotton, J.L. \& Tuttle, J.M. (1986). Employee turnover: A meta-analysis and review with implications for research. Academy of Management Review, 11 (1), 55-70

10. Cropanzano, R., James, K. \& Konovsky, M.A. (1993). Dispositional affectivity as a predictor of work attitudes and job performance. Journal of Organizational Behavior, 14, 595-606 
11. Dahling, J.J., Whitaker, B.G. \& Levy, P.E. (2008). The Development and Validation of a New Machiavellianism Scale, Journal of Management, 20 (10), 1-39

12. E.R.C. (Ethics Resource Center) (2005). The 2005 National Business Ethics Survey, [On line]. Available from www.ethics.org/nbes/nbes2005/release.html [Accessed on August 2006].

13. Falk, R.F. \& Miller, N.B. (1992). A primer for soft modelling, Akron, OH: The University of Akron Press

14. Griffeth, R.W., Hom, P.W. \& Gaertner, S. (2000). A Meta-Analysis of Antecedents and Correlates of Employee Turnover: Update, Moderator Tests and Research Implications for the Next Millenium. Journal of Management, 26 (3), 463-488.

15. Gunnthorsdotir, A., McCabe, K. \& Smith, V. (2002). Using the Machiavellianism instrument to predict trustworthiness in a bargaining game. Journal of Economic Psychology, 23, 49-66.

16. Hackman, J.R. \& Oldham, G.R. (1980). Work Redesign. Reading, MA: Addison-Wesley

17. Hulland, J. (1999). Use of partial least square (PLS) in strategic management research: a review of four recent studies. Strategic Management Journal, 20, 195-204,

18. Hunt, S.D. \& Chonko, L.B. (1984). Marketing and Machiavellianism. Journal of Marketing, 48, 30-42.

19. Hunt, S.D., Chonko, L.B. \& Wood, V.R. (1985). Organizational commitment and Marketing. Journal of Marketing, 49, 112-126

20. Hunt, S.D. \& Vitell, S. (1993). The general theory of marketing ethics: A retrospective and revision. In N.C. Smith \& A. Q. John (Eds.): Ethics in marketing. Homewood, IL: Irwin Inc

21. Kleinbaum, D.G., L.L. Kupper \& K.E. Mulle (1988). Applied regression analysis and other multivariate analysis methods. Boston: PWS-Kent Publishing Company

22. Konovsky, M.A. \& Cropanzano, R. (1991). The perceived fairness of employee drug testing as a predictor of employee attitudes and job performance. Journal of Applied Psychology, 76, 698-707

23. Kristof-Brown, Zimmerman, R.D. \& Johnson, E.C. (2005). Consequences of individuals' fit at work: A meta-analysis of person-job, person-organization, person-group and person-supervisor fit, Personnel Psychology, 58, 281-342.

24. MacKenzie, S.B., P.M. Podsakoff \& Jarvis, C.B. (2005). The problem of measurement model misspecification in behavioural and organizational research and some recommended solutions. Journal of Applied Psychology, 90, 710-730

25. McCutcheon, L.E. (2003). Machiavellianism, belief in a just world and the tendency to worship celebrities. Current Research in Social Psychology, 8 (9). Electronic Journal. Available from www.uiowa.edu/ grpproc/crisp/crisp.html. [Accessed on July 2007].

26. Peterson, D.K. (2003). The relationship between ethical pressure, relativistic moral beliefs and organizational commitment, Journal of Managerial Psychology, 18 (6), 557-572,

27. Podsakoff, P.M., MacKenzie, S.B., Lee J.Y. \& Podsakoff, N.P. (2003). Common Method Biases in Behavioral Research: A Critical Review of the Literature and Recommended Remedies. Journal of Applied Psychology, 88, 5, 879-903

28. Trevino, L.K. \& Nelson, K.A (2004). Managing business ethics: Straight talk about how to do it right. New York: John Wiley \& Sons

29. Valentine, S., Greller, M.M. \& Richtermeyer, S. (2006). Employee job response as a function of ethical context and perceived organization support. Journal of Business Research, 59, 582-588

30. Wilson, D.S., Near, D. \& Miller, R.R. (1996). Machiavellianism: A synthesis of the evolutionary and psychological literatures. Psychological Bulletin, 119, 285-299

31. Wold, H. (1979). Model construction and evaluation when theoretical knowledge is scarce: An example of the use of Partial Least Squares. Cahiers du Département D Économétrie, Géneve, Université de Genève. 
NOTES 